\title{
Matrix Gla protein in turbot (Scophthalmus maximus): Gene expression analysis and identification of sites of protein accumulation
}

\author{
Vânia P. Roberto a , Sofia Cavaco ${ }^{\text {a }}$, Carla S.B. Viegas ${ }^{\text {a }}$, Dina C. Simes ${ }^{a}$, Juan-Bosco Ortiz-Delgado ${ }^{\text {a,b }}$, \\ M. Carmen Sarasquete ${ }^{\mathrm{b}}$, Paulo J. Gavaia ${ }^{\mathrm{a}}$, M. Leonor Cancela ${ }^{\mathrm{a}, *}$ \\ a CCMAR, Universidade do Algarve, 8005-139 Faro, Portugal \\ b Institute of Marine Sciences of Andalucía, CSIC, Polígono Río San Pedro Apdo Oficial, 11510 Puerto Real, Cádiz, Spain
}

\section{A R T I C L E I N F O}

\section{Article history:}

Received 22 August 2007

Received in revised form 31 May 2009

Accepted 13 June 2009

\section{Keywords:}

Turbot Mgp

Gene expression

Soft tissue accumulation

Heart

Vertebrae

Branchial arches

\begin{abstract}
A B S T R A C T
Matrix Gla protein (Mgp) is a secreted vitamin K-dependent extracellular matrix protein and a physiological inhibitor of calcification whose gene structure, amino acid sequence and tissue distribution have been conserved throughout evolution. In the present work, the turbot (Scophthalmus maximus) mgp cDNA was cloned and the sequence of the deduced protein compared to that of other vertebrates. As expected, it was closer to teleosts than to other vertebrate groups but there was a strict conservation of amino-acids thought to be important for protein function. Analysis of mgp gene expression indicated branchial arches as the site with higher levels of expression, followed by heart, vertebra and kidney. These results were confirmed by in situ hybridization with a strong mgp expression in branchial arch chondrocytes.

Mgp was found to accumulate in gills where it appeared to be restricted to chondrocytes from branchial filaments, while in vertebrae it was localized in vertebral end plates, in growth zones, in vertebral arches and spines and in notochord cells. In the soft tissues analysed, Mgp was mainly detected in kidney and heart, consistent with previous data and providing further evidence for a role of Mgp as a calcification inhibitor and a modulator of the mineralization process. Our studies provide evidence that turbot, an important new species for aquaculture, is also a useful model to study function and expression of Mgp.
\end{abstract}

(c) 2009 Elsevier B.V. All rights reserved.

\section{Introduction}

Matrix $\gamma$-carboxyglutamic acid (Gla) protein (Mgp) is a vitamin Kdependent protein known for its capability of binding mineral ions through its gamma-carboxylated glutamic acid residues. Mgp is normally found associated with the organic matrix of cartilage and bone in vivo, and it is expressed in various vertebrate tissues such as cartilage, kidney, lung, aorta, bone and tooth (Fraser and Price, 1988; Hao et al., 1995; Hashimoto et al., 2001; Hale et al., 1988). Although a wide range of cell types express Mgp, only chondrocytes, endothelial cells and VSMC (vascular smooth muscle cells) synthesize significant levels of Mgp in vivo (Conceição, et al., 2002; Luo et al., 1997; OrtizDelgado et al., 2005, b; Simes et al., 2003). After the discovery of Mgp in various soft tissues, it was proposed that this protein could act as a local inhibitor of mineralization (Fraser and Price, 1988). Accordingly, a number of later studies using various genetic and biochemistry approaches established Mgp as the first in vivo calcification inhibitor, although its molecular mechanism of action remains incompletely understood (Braam et al., 2000; Luo et al., 1997; Meier et al., 2001; Proudfoot et al., 1998; Speer et al., 2002; Wallin et al., 2001). Mgp

\footnotetext{
* Corresponding author. Tel.: +34 351289800 971; fax: +34 351289818353 .

E-mail addresses: vroberto@ualg.pt (V.P. Roberto), dsimes@ualg.pt (D.C. Simes), pgavaia@ualg.pt (P.J. Gavaia), lcancela@ualg.pt (M.L. Cancela).
}

plays also a role in chondrocyte differentiation and maturation and is a key factor for normal endochondral and intramembranous ossification (Luo et al., 1997; Newman et al., 2001; Yagami et al., 1999).

The skeleton is highly diversified throughout fish species and different aquatic habitats and is responsible for body shape, movement and muscle attachment, as well as protection of internal organs. It also plays an important role in physiological functions such as feeding and reproduction, and is the major calcium and/or phosphate reservoir for many species (Du et al., 2001; Lagler et al., 1987; Marshal and Hughes, 1985; Walker and Liem, 1994). For this study, we have selected a marine teleost species which undergoes major alterations in its skeletal morphology during development, the pleuronectiform Scophthalmus maximus, commonly known as turbot. This species is becoming progressively more important for aquaculture given its high commercial value, and at present its rate of production is increasing worldwide. However, there is a scarce knowledge on the mechanisms involved in turbot skeletal development, remodelling during metamorphosis and subsequent growth maintenance. Therefore, the main objective of this work was to characterize the structure of the cartilaginous tissues of this species through an extensive histomorphological analysis. Furthermore, and given the possible involvement of Mgp in these processes, we have also identified the major sites of turbot $m g p$ gene expression and protein accumulation and compared the results with those previously obtained for other fish. 


\section{Materials and methods}

\subsection{Specimen collection and processing}

Turbot juveniles $(\sim 6 \mathrm{~g})$ were collected from an aquaculture company (STOLT seafarm, Galicia-Spain) in collaboration with the Institute of Marine Sciences of Andaluzia (ICMAN-CSIC, Cadiz). Juveniles were anaesthetized in 2-phenoxyethanol (Sigma, St Louis, MO) and sacrificed by post-cranial sectioning of the spinal chord. Samples of various organs were either collected in TRIZOL Reagent (Gibco-Invitrogen) and preserved at $-80{ }^{\circ} \mathrm{C}$ for subsequent RNA purification, or fixed in buffered $4 \%$ paraformaldehyde ( $\mathrm{pH} 7.4$ in PBS) for $24 \mathrm{~h}$ at $4{ }^{\circ} \mathrm{C}$. After fixation, samples were either immediately preserved in methanol at $-20^{\circ} \mathrm{C}$ or decalcified in ethylenediaminetetraacetic acid solution (EDTA $10 \%$ /formaldehyde $2 \%$ ) at $4{ }^{\circ} \mathrm{C}$ and then preserved in methanol at $-20{ }^{\circ} \mathrm{C}$.

\subsection{RNA purification}

Total RNA was purified from turbot tissues (vertebrae, liver, kidney, heart and branchial arches) using the TRIZOL (Gibco) method, according to supplier instructions. Integrity of purified RNA was evaluated by gel electrophoresis.

\subsection{Molecular cloning of mgp cDNA}

The turbot mgp sequence was obtained using $1 \mu \mathrm{g}$ of total RNA derived from heart, that was reverse-transcribed at $37^{\circ} \mathrm{C}$ for $1 \mathrm{~h}$, using the Moloney Murine Leukemia Virus Reverse Transcriptase (M-MLVRT, Invitrogen) and a reverse oligo(dT)-adapter (5'-ACGCGTCGACCTCGA GATCGATG $\left.(\mathrm{T})_{18^{-}} 3^{\prime}\right)$. Amplification of the $3^{\prime}$ end of mgp cDNA was performed by the polymerase chain reaction (PCR) using one forward oligonucleotide designed according to Sparus aurata mgp cDNA (Pinto et al., 2003) (spMGPcF2: 5'-GAGGACTACTCGCCCTGCCGCTTCT-3') and the universal dT adapter (5'-ACGCGTCGACCTCGAGATCGATG-3'). The corresponding PCR reactions were conducted for 30 cycles ( 1 cycle: $95^{\circ} \mathrm{C}: 30 \mathrm{~s}, 60{ }^{\circ} \mathrm{C}: 45 \mathrm{~s}$, and $72{ }^{\circ} \mathrm{C}: 60 \mathrm{~s}$ ), preceded by $5 \mathrm{~min}$ of an initial denaturing step at $95^{\circ} \mathrm{C}$, and followed by a 10 min final extension at $72{ }^{\circ} \mathrm{C}$, with Taq DNA polymerase (Sigma).

Poly- $A^{+}$RNA from turbot was purified from $500 \mu \mathrm{g}$ of total RNA (a mixture of heart, kidney, branchial arches, vertebrae and liver in equal amounts) with the Oligotex mRNA Midi Kit (Qiagen). $1 \mu \mathrm{g}$ of this mRNA was used to construct one Marathon cDNA library (BD Bioscience Clontech) and the $5^{\prime}$ end of $m g p$ cDNA was cloned following $5^{\prime}$ rapid amplification of cDNA ends (RACE)-PCR with the Marathon cDNA Amplification Kit (BD Bioscience Clontech), using Advantage cDNA polymerase, the AP1 primer and the mgp specific primer RvMGP1R ( $5^{\prime}-$ TGGATAGAGAACGAAACACTTAATTCAAGCGTA-3'), designed within the partial sequences previously obtained. Amplification conditions were those suggested by the supplier:

All PCR products obtained were fractionated by agarose gel electrophoresis, purified from the gel and cloned into $\mathrm{pCR}^{\mathrm{II}} \mathrm{TOPO}$ (Invitrogen). Final identification was achieved by DNA sequence analysis using SP6 vector specific primer at Macrogen Inc. (South Korea).

\subsection{Molecular cloning of partial $18 S$ ribosomal RNA}

Turbot 18S ribosomal RNA was cloned using $1 \mu \mathrm{g}$ of total RNA derived from liver and RT-PCR was conducted as described above, using primers Cod18SRNA01F ( $5^{\prime}$-CACATCCAAGGAAGGCAGCAGGCG-3') and Cod18SRNA01R ( 5'-(AG)GT(CT)GGCATCGTTTA(CT)GGTCGCAACTA-3'), designed based on the conserved sequences derived from the nucleotide alignment of $18 \mathrm{~S}$ ribosomal RNA sequences available for different species. The PCR products were analysed as described above and partial 18S rRNA sequence was obtained (GenBank accession no. DQ302409).

\subsection{Analysis of gene expression by real-time quantitative PCR ( $q P C R$ )}

Real-time qPCR assays were performed using iCycler PCR system and software to quantify nucleic acids (Bio-Rad, Richmond, USA). Total RNA $(1 \mu \mathrm{g})$ was reverse-transcribed as described above. Reaction mixture containing $1 \times$ iQ SYBR Green I mix (Bio-Rad), $0.2 \mu \mathrm{M}$ of forward and reverse primers and $5 \mathrm{ng}$ of reverse-transcribed RNA was submitted to the following PCR conditions: 13 min at $95^{\circ} \mathrm{C}, 50$ cycles (each cycle is $30 \mathrm{~s}$ at $95^{\circ} \mathrm{C}, 15 \mathrm{~s}$ at $\left.68^{\circ} \mathrm{C}\right) .18 \mathrm{~S}$ ribosomal relative gene expression was used to normalize mgp gene expression levels and the reference sample was the liver. Fragments of 144-bp for mgp cDNA and 194-bp for 18S ribosomal cDNA were amplified using the primer sets SmMGP02F (5'-CCCCAG GATGAGGAGCCTTCTTCG-3')/SmMGP02R (5'-TGTGGCGTGAAG GAGTTGGCT-3') and Sm18S02F (5'-GCCACCGTCTCCCAGCCCCT-3')/ Sm18S02R (5'-CCCAGTTCAGAGAGAGAAAACCCACA-3'), respectively.

\subsection{Histological procedures}

Turbot liver, spleen, heart, kidney, gut, vertebrae and branchial arches were included in paraffin blocks, sectioned $(5-7 \mu \mathrm{m})$ and collected in TESPA (3-aminopropyltriethoxysilane, Sigma)-coated slides. Staining was carried out with alcian blue 8GX (pH 1.0) (CI 74240; Sigma), for cartilaginous tissue detection, and with Harris haematoxylin-eosin (HE) (CI 75290, Sigma and CI 1143463, Merck), for identification of structures and morphological features. After staining, sections were dehydrated and mounted with EUKIT (Merck).

\subsection{Purification of Mgp from vertebra and heart tissues}

Vertebra from adult S. maximus were crushed in liquid nitrogen, acid extracted and a crude precipitate was obtained as described in Simes et al., 2003. Following dialysis against $50 \mathrm{mM} \mathrm{HCl}, 30-50 \mu \mathrm{g}$ of total protein from the resulting Mgp-containing extract were loaded into parallel lanes of a 4-12\% SDS-PAGE gel (Nupage, Invitrogen) and electrophoresed. The gel was then cut into two halves and stained with either CBB for total protein detection or DBS for specific Gla residue detection, as described (Simes et al., 2003).

The hearts from four S. maximus adult specimens were cleaned from blood by extensive washing with milli-Q water then frozen in liquid nitrogen and ground with a mortar and pestle. The resulting tissue powder was extracted using a 10-fold excess $(\mathrm{w} / \mathrm{v})$ of $6 \mathrm{M}$ guanidine$\mathrm{HCl}$ solution with vigorous stirring at room temperature for $24 \mathrm{~h}$ followed by a 10 min centrifugation at $10,000 \mathrm{rpm}$, at room temperature. The tissue pellet was subjected to a similar second extraction procedure during $24 \mathrm{~h}$. Supernatants from both extractions were mixed, dialyzed (SpectraPor 3; Spectrum, Gardena, CA, USA) against $50 \mathrm{mM} \mathrm{HCl}$ at $4{ }^{\circ} \mathrm{C}$, cleared by centrifugation at $\left(10,000 \mathrm{rpm}, 10 \mathrm{~min}, 4^{\circ} \mathrm{C}\right)$ and total supernatant protein content was as previously described (Simes et al., 2004). The presence of Mgp in both dialyzed guanidine extracts was analysed by western blot. In brief, a total of $200 \mu \mathrm{g}$ of protein from each heart extract (samples 1 and 2) were dissolved in SDS reducing sample buffer containing reducing agent (NuPage, Invitrogen, La Jolla, CA,USA), applied to a $4-12 \%$ gradient polyacrylamide precast gel containing $0.1 \%$ SDS (NuPage, Invitrogen) and fractionated at constant $140 \mathrm{~V}$.

Western-blot analysis for both validation of ArMgp antibody (developed against Argyrosomus regius, meagre, Mgp) and detection of Mgp in heart samples was performed as described (Simes et al., 2004) using 1:250 dilution of ArMgp primary polyclonal antibody. Immunoreactive protein bands were detected using alkaline phosphatase-labelled goat anti-rabbit IgG antibody (Gibco-BRL, Paisley, UK) diluted 1:20,000 in TBST and visualized using NBT/BCIP substrate solution (Sigma).

\subsection{Immunohistochemistry}

Immunohistochemistry was performed with ArMgp primary antibodies validated for turbot Mgp by western blotting 
(supplementary Fig. 5), using as secondary antibodies peroxidaseconjugated or FITC-conjugated goat anti-rabbit IgG, as described for other species (Simes et al., 2003). .Histological sections were incubated overnight with rabbit anti-Mgp polyclonal antibody, washed and incubated for another $2 \mathrm{~h}$ with goat anti-rabbit IgG peroxidase-conjugated (Sigma), then stained with DAB (3,3'-Diamino Benzidine, Sigma) as described (Simes et al., 2003). The endogenous peroxidase activity was blocked with $3 \% \mathrm{H}_{2} \mathrm{O}_{2}$ before immunostaining. Results were visualized with a BX-41 Olympus light microscope equipped with a C3030 Olympus digital camera.

Immunofluorescent Mgp detection procedure was similar to that described above but incubation with goat anti-rabbit IgG FITCconjugated (Sigma) was performed in a humidified dark chamber. Sections were washed and mounted with glycerol immediately before observation. Results were visualized with a Leica DMLB fluorescence microscope equipped with a Leica DC 300 FX camera.

Specificity of the immunoreactions was confirmed by negative controls where (1) primary antibody was replaced with BSA, (2) secondary antibody was replaced with Coon's buffer or (3) either primary or secondary antibodies were omitted.

\subsection{In situ hybridization}

Sense and anti-sense RNA probes were synthesised from a 575-bp partial sequence of turbot mgp cDNA (spanning from nucleotide 247 to the $3^{\prime}$ end of the CDNA), linearized with ApaI and transcribed with SP6 RNA polymerase to generate a sense probe, or linearized with SpeI and transcribed with T7 RNA polymerase to generate an anti-sense probe. Quality of synthesised probes was verified by agarose gel electrophoresis. Both probes were then labelled with digoxigenin using a RNA labelling kit (Roche, Mannheim, Germany) according to manufacturer's instructions.

Treatment of slides and hybridization conditions were performed as previously described (Viegas et al., 2008). Hybridization was performed at $65{ }^{\circ} \mathrm{C}$ overnight in a humidified chamber. After hybridization, the sections were washed two times, each of them for $30 \mathrm{~min}$ at $65^{\circ} \mathrm{C}$, in $50 \%$ formamide $/ 50 \% 2 \times$ SSC, then a third time under similar conditions but using $50 \%$ formamide $/ 50 \% 0.2 \times$ SSC. Hybridized probe was detected with the alkaline phosphatase-coupled anti-digoxigenin-AP antibody (Boehringer, Mannheim, Germany) and NBT/BCIP substrate solution (Sigma) as described (Simes et al., 2003). The controls included hybridization with the sense probe, RNase treatment before hybridization and absence of either anti-sense RNA probe or anti-digoxigenin antibody. All three control experiments showed no detectable signals (results not shown).

\subsection{Statistical analysis}

Statistical analysis of expression levels was first performed using ANOVA with a $p$-value of $<0.001$, followed by the Holm-Sidak method, with a $p$-value of 0.05 using SigmaStat ${ }^{\circledR}$ version 3.5.

\section{Results}

\subsection{Identification and molecular cloning of turbot mgp}

The complete nucleotide sequence of turbot mgp cDNA (GenBank accession no. DQ304476) was obtained by a combination of RT- and 5' RACE-PCR. The longest mgp cDNA obtained spans 864 base pairs (bp) and comprises an open reading frame (ORF) of $354 \mathrm{bp}$ (Fig. 1)

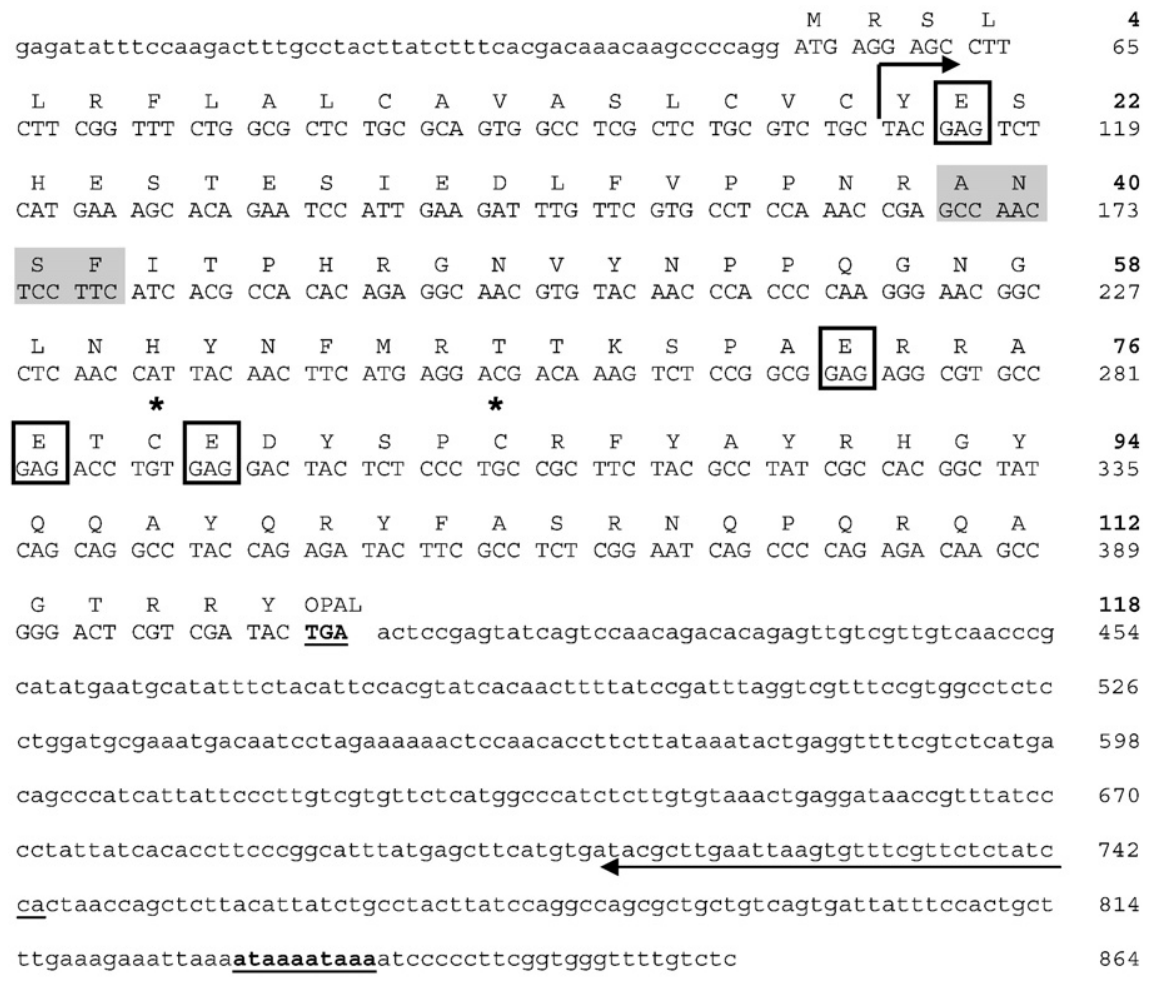

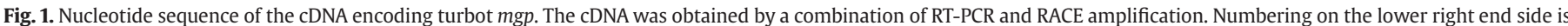

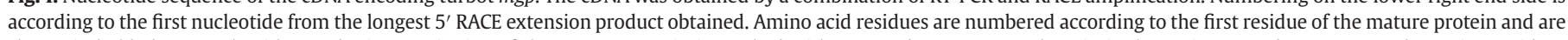

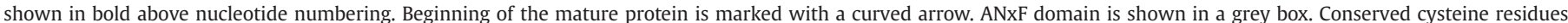

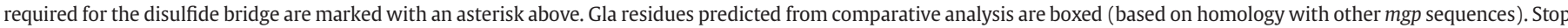

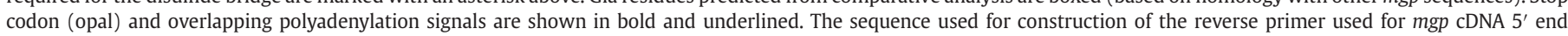
amplification is denoted by a horizontal arrow. 


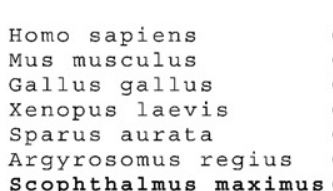

Scophthalmus maximus

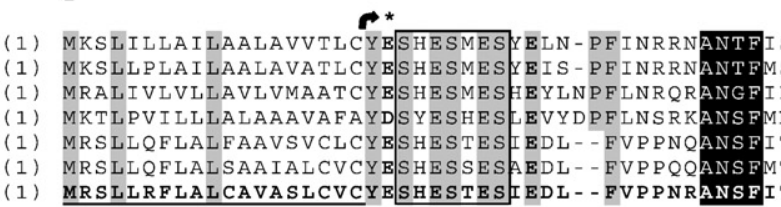

Fi PQQRWRAKVQERIRER - - - - - - - - SKPVHELNREACDDYRL

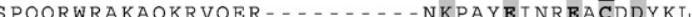
RDDTGIRAVIQRRIRER - - - - - SSQK - NQRMNER TRER - - N IT PQ - - RGNVYSP PRGNGLNNYNLMRKVKS PABRRAET TEDYSP MT PQ - - - RGNAYSPPRGN - GNNFNLMRTVKSPAERRAET CEDYSP ITPH - - - RGNVYNP PQGNGLNHYNFMRTTRSPAERRAETCEDYSP

Homo sapiens

Mus musculus

Gallus gallus

Xenopus laevis

Sparus aurata

Argyrosomus regius

$90-124$

90

(90) CERYAMVYGYNAAYNRYFRKRRGAK . . . . . .

(90) CERYAMVYGYNAAYNRYFRQRRGAKY - . . . .

(91) CEQYALNHGYPAAYRHYFGRRRNK - . . . . . .

(91) CBRYALRYGFTAAYKRYFGQRRGEKK - . - . - .

(87) CRFYAYRHGFQQAYQRYFGARNTPORP - - AATRRY

(87) CRFYAYRHGFQQAYQRYFGSGTHPQQRPAAAARRY

Scophthalmus maximus (87) CRFYAYRHGYQQAYQRYFASRNQPQRQ- -AGTRRY

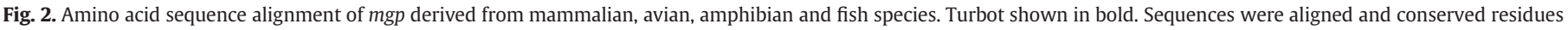

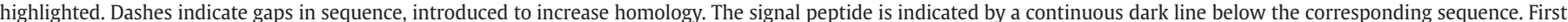

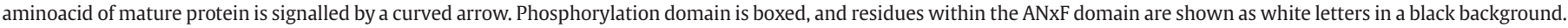

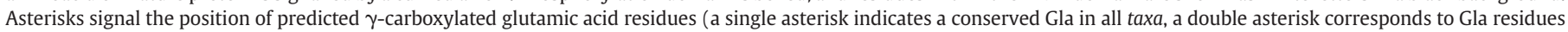

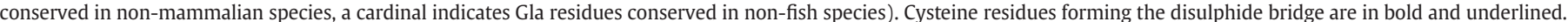

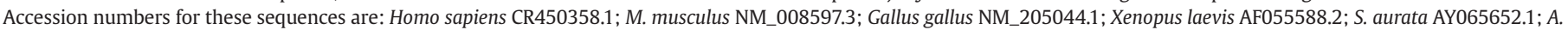
regius AF334473.1; S. maximus DQ304476.

encoding a polypeptide of 117 amino acid residues (aa), and $5^{\prime}$ and $3^{\prime}$ UTRs of 53 and $457 \mathrm{bp}$, respectively. The site of insertion of the poly-A tail is located 25 bp after two consensus consecutive polyadenylation signals (aataaa). By comparison with the protein sequences deduced from the complete cDNAs identified from other vertebrates, we hypothesize that the turbot $m g p$ contains a 19 aa signal peptide, followed by a mature protein of 98 residues. Amino acid sequence alignments (Fig. 2) allowed identification of residues and domains conserved between turbot and other Mgp sequences, including: (1) a transmembrane signal peptide to control protein entry into the secretory pathway; (2) a phosphorylation domain; (3) a $\gamma$-glutamyl carboxylation recognition site; (4) an ANxF proteolytic cleavage site thought to be involved in post-translational processing; (5) two invariable cysteine residues required for establishing an intramolecular disulphide bridge; and (6) a C-terminal Gla domain where the majority of the Glu residues are expected to be $\gamma$-carboxylated, and thus responsible for the high affinity binding of calcium ions.

\subsection{Tissue distribution of mgp gene expression}

Distribution and levels of turbot mgp gene expression in the different tissues were determined by quantitative real-time PCR and in situ hybridization to attempt to correlate the relative levels of

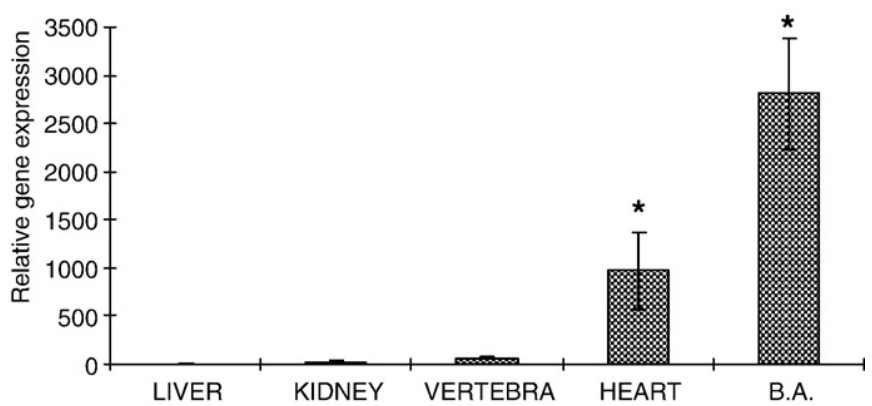

Fig. 3. Relative turbot $m g p$ gene expression in tissues. Liver was selected as reference sample and the corresponding mgp gene expression levels were arbitrarily set to 1 . Values are the mean of 3 independent real-time qPCR experiments. Turbot $18 \mathrm{~S}$ (accession number DQ302409) was used to normalize mgp gene expression to the total amount of RNA in the sample. Asterisk indicates that expression levels are significantly different from those detected in all others samples in the figure. (B.A. - branchial arches.) gene expression with the sites where expression occurred within the tissues analysed.

\subsubsection{Quantitative real-time $P C R$}

From all tissues analysed, liver had the lowest levels of mgp expression and thus was selected as reference sample. No significant differences were found between levels detected in liver, kidney and vertebrae for mgp mRNA. Branchial arches had the highest levels of mgp gene expression (over 2500 fold higher than the reference sample) while heart was found to exhibit close to 1000 fold increase over reference (Fig. 3).

\subsubsection{In situ hybridization}

Confirming the qPCR data, mgp was found to be strongly expressed by chondrocytes in branchial arches. A strong signal was observed in all cartilaginous structures including in hyaline cartilage of ceratobranchial and Zellknorpel cartilages of branchial filaments (Fig. 4.1 and 4.2). No mgp expression was detected in adjacent bony tissues (Fig. 4.1). In vertebrae, we detected expression of mgp only in chordoblasts (Fig. 4.3) and in cell population of the growth zone, known to contain chondroblast and osteoblast precursors (Fig. 4.4). Cartilaginous islets at the base of vertebral arches also showed expression of $m g p$ in some chondrocytes (not shown), although at much lower levels than observed in branchial arch cartilages. From all soft tissues analysed, only kidney and heart showed significant levels of expression of mgp. In heart, mgp mRNA was associated to cardiomyocytes throughout the cardiac muscle (Fig. 4.5) while in kidney (Fig. 4.6), mgp mRNA was localized in cells from endothelium of urinary tubules and in some glomeruli.

\subsection{Immunolocalization of Mgp and tissue characterization}

The antibodies developed against A. regius Mgp were validated for the turbot protein using Mgp extracted and purified from S. maximus vertebra. DBS staining permitted the identification of a Gla containing protein in sample extracts (Fig. 5.1) corresponding to a single immunoreactive band observed in western blotting with anti-ArMgp with a migration behaviour (14-18 $\mathrm{kDa}$ ) similar to that previously observed for other fish Mgp entities (Simes et al., 2004). Similarly, SDS-PAGE electrophoresis of guanidine-HCL extracts obtained from heart, followed by blotting onto nitrocellulose membranes and incubation with anti-ArMgp polyclonal antiserum, revealed the 

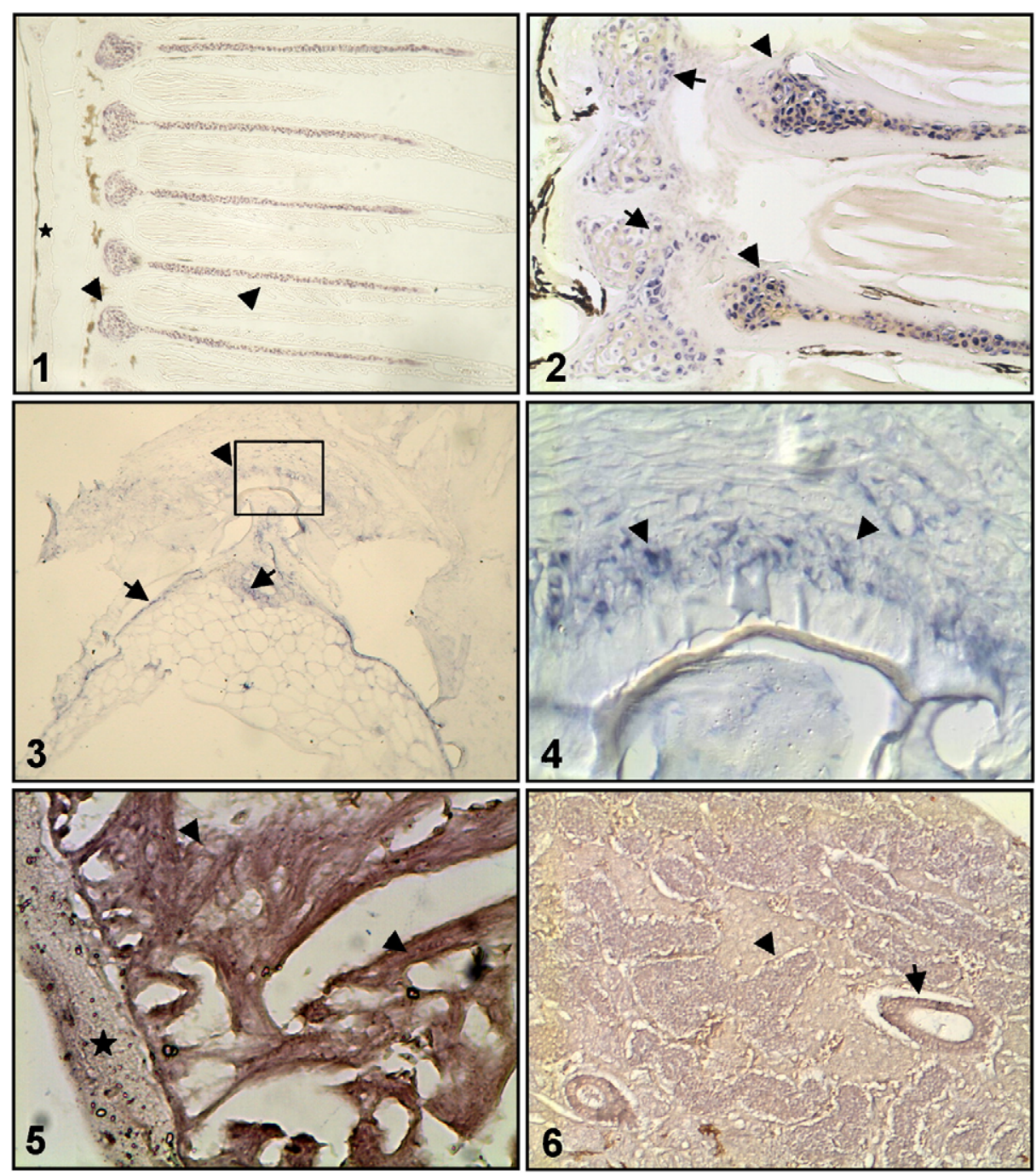

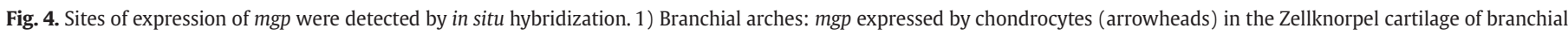

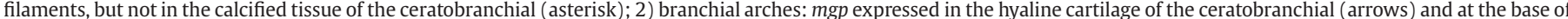

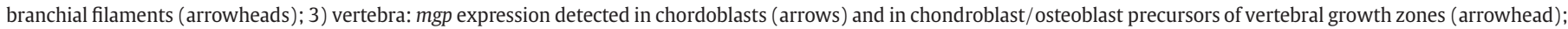

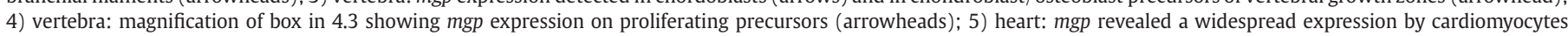

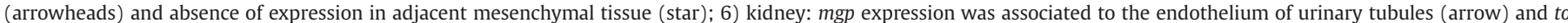
glomeruli (arrowhead).

presence, in heart extract, of an immunoreactive band corresponding to Mgp (Fig. 5.2).

\subsubsection{The gills of turbot}

In turbot, the gills consist of four to five branchial arches on each side of the esophagus that attach 2 sets of branchial filaments composed by the primary and secondary lamellas. Both branchial arches and primary lamella have a central core of cartilage (nomenclature used for cartilage follows that of Benjamin et al. (1992)), but while Zellknorpel cartilage, in branchial filaments, present proliferating chondrocytes, those of ceratobranchial contain mature chondrocytes immersed in a homogeneous (hyaline) cartilage matrix. ECM from both cartilages was stained with alcian blue, as seen in the basal part of branchial filaments (Fig. 6.1 and 6.5). With HE, bone matrix from ceratobranchial and acidophilic structures stained with eosin while nuclei of chondrocytes from branchial filaments stained with haematoxylin (Fig. 6.2 and 6.3). Using immunofluorescence and peroxidase-conjugated immunodetection, Mgp was found to accumulate mainly within proliferating chondrocytes from branchial filaments, and it was not detected in the extracellular matrix of cartilage (Fig. 6.4 and 6.6).

\subsubsection{The vertebrae of turbot}

The turbot vertebra is composed by the vertebral centrum (spongiosa) and 2 vertebral end plates. Bone matrix at vertebral end plates and centrum was stained with eosin, indicating a basic nature (Fig. 7.1). Mgp was immunodetected in the bone matrix of vertebral end plates and in vertebrae growth zones, within the contact area of opposing vertebral body end plates (Fig. 7.2 and 7.3). The bone matrix was clearly stained by alcian blue, although no staining was observed in the growth zones with this technique (Fig. 7.4).

In the centre of two adjacent vertebrae, and filling the intervertebral space, is the notochord (Fig. 7.1 and 7.2). This tissue is composed by an acellular, fibrous elastic sheath, covering a glycosaminoglycan-rich collagenous layer (Grotmol et al., 2005; Sanatamaría et al., 2005), that encloses and constrains the net of chordocytes in the inner core, surrounded by an outer layer of chordoblasts. Using HE, the chordoblast nucleus is stained by haematoxylin while the notochord is clearly stained with eosin, (Fig. 7.1). Mgp was found to accumulate in the notochord cells, both in chordoblasts and chordocytes, as detected by both immunocytochemistry and immunofluorescence (Fig. 7.2 and 7.3). In contrast, no immunostaining was observed in the notochordal 
1

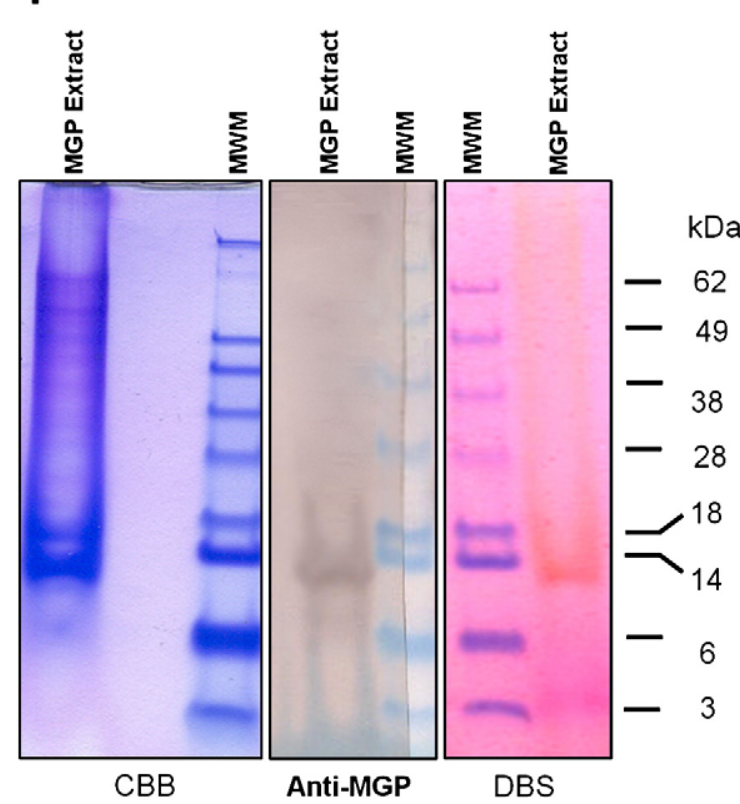

2

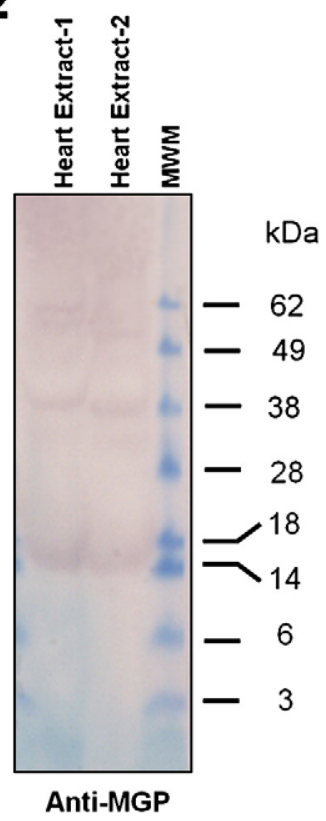

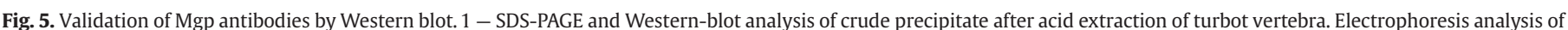

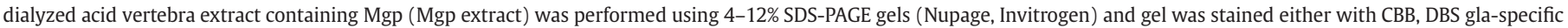

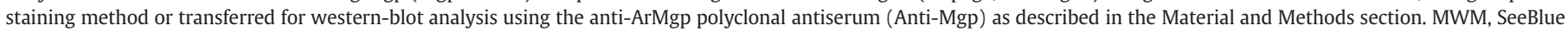

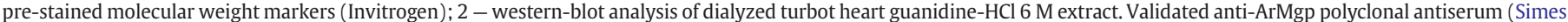

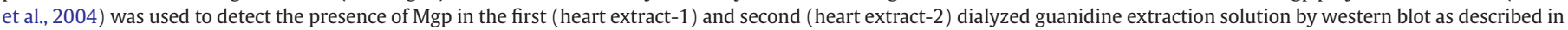
the Materials and Methods. MWM, SeeBlue pre-stained molecular weight markers (Invitrogen).

sheath (Fig. 7.4, stained by alcian blue) confirming the cellular location of Mgp.

Each trunk vertebrae comprises one haemal and one neural process. Together, the haemal arches form the haemal canal which carries the primary blood vessels, while the neural arches accommodate the spinal cord, and together form the neural canal. From each neural and haemal arch, a spine extends providing anchorage for muscle attachment. Mgp was immunodetected in vertebral arches and spines, by both techniques used (Fig. 7.5 and 7.6), and appeared to be restricted to the corresponding mineralizing fronts.

\subsubsection{Soft tissues of turbot}

From all turbot soft tissues analysed (heart, gut, kidney, liver and spleen), accumulation of Mgp was immunodetected only in the endothelium of urinary tubules of kidney (Fig. 8.1 and 8.2) and in heart cardiomyocytes (Fig. 8.3) suggesting a specific function in these two organs.

\section{Discussion}

\subsection{There is a high degree of evolutionary conservation among fish Mgp} sequences

Comparison of turbot Mgp with sequences from other organisms indicated a higher degree of identity with homologous sequences from fish species (ranging from $80 \%$ to $60 \%$ amino acid conservation) than with other groups of vertebrates (ranging from $40 \%$ to $30 \%$ amino acid conservation). However, the evolutionary conservation of many invariant residues identified from the alignment of all vertebrate Mgp sequences, suggests that they are required for maintenance of a correct protein structure and/or to preserve a critical function. Among the unique characteristics that distinguish Mgp from other vitamin Kdependent proteins is the lack of a pro-peptide, with the gammacarboxylase recognition sequence encoded inside the mature protein (Cancela et al., 2001; Price et al., 1987), demonstrating that gamma- carboxylation and secretion of this VKD protein are not directly related to the proteolytic cleavage of a pro-peptide domain (Price et al., 1987). An ANxF putative proteolytic cleavage site (reviewed in Laizé et al., 2005) and three highly conserved serine phosphorylation sites near the N-terminus of all known Mgps (Laizé et al., 2005; Price et al., 1994; Simes et al., 2003) are some of the potential targets for post-translational events that may alter the activity and/or properties of Mgp.

4.2. The highest levels of turbot mgp gene expression are found in branchial arches and heart

Previous findings showed that tissue distribution of $m g p$ in fish (Pinto et al., 2003; Simes et al., 2003) essentially parallels that seen in mammals (Fraser and Price, 1988; Luo et al., 1997) and amphibians (Cancela et al., 2001). In this work, high levels of mgp gene expression were detected in branchial arches by qPCR. Since branchial arches contain cartilage with chondrocytes, which secrete mgp, this justifies the high levels detected. Results obtained by in situ hybridization confirmed the previous statement by revealing a strong $m g p$ expression associated with chondrocytes in branchial arches and branchial filaments (Fig. 4). This could be related to Mgp proposed role in maintenance of a non calcified cartilage matrix, but also as a possible mediator of calcium metabolism occurring at the gill level. Accordingly, a strong mgp expression associated with these structures was previously observed in other fish species such as gilthead seabream (S. aurata), zebrafish (Danio rerio) and Senegalese sole (Solea senegalensis) (Gavaia et al., 2006; Pinto et al., 2003). Furthermore, the purification of sizeable amounts of Mgp from fish was only possible using calcified branchial arches (Simes et al., 2003) confirming the high content of Mgp in these structures, probably due to its high affinity for calcified matrices.

After branchial arches, heart was the other tissue where significant levels of mgp expression were detected by qPCR. Simes et al. (2003) reported heart as the major site for $m g p$ expression in adult meagre, 

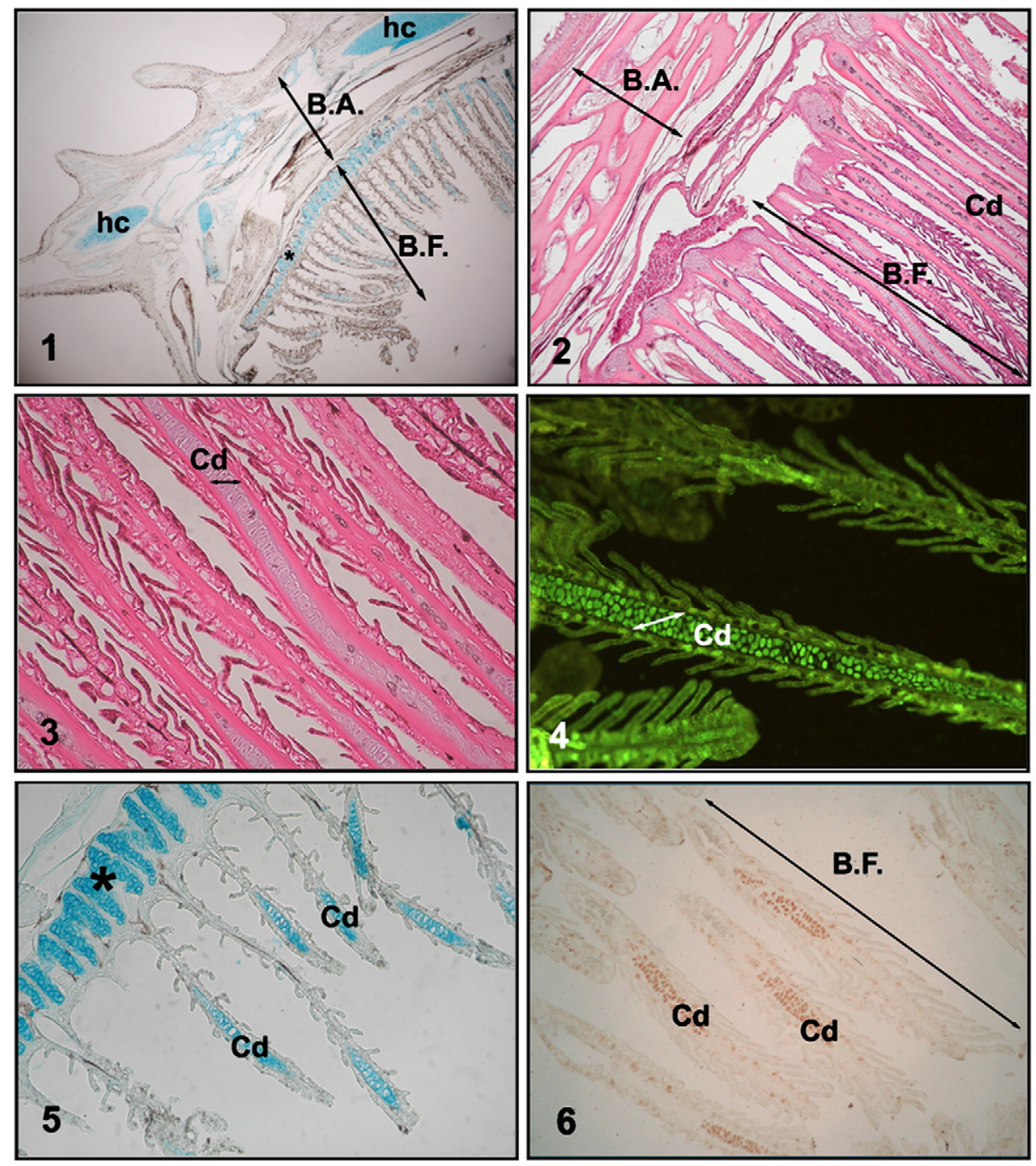

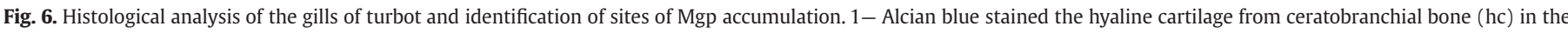

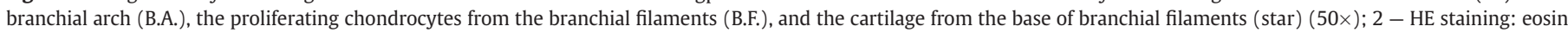

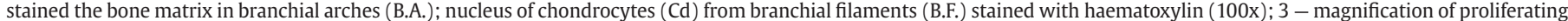

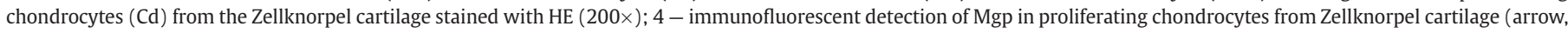

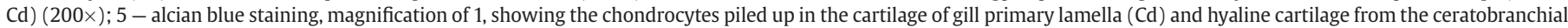
(asterisk) (200×); 6 - confirmation of the site of Mgp accumulation in the branchial filaments (B.F.), as shown in 4, by peroxidase-conjugate immunodetection (Cd) (100×).

followed by branchial arches, and Pinto et al. (2003) reported levels of mgp expression in heart almost equivalent to those observed in branchial arches for juvenile gilthead seabream. The high expression levels of mgp observed in heart are in agreement with those previously observed by others for fish (Simes et al., 2003), amphibians (Cancela et al., 2001) and mammals (Fraser and Price, 1988). Our results by in situ hybridization confirmed that cardiomyocytes were expressing $m g p$. Furthermore, localization of $m g p$ mRNA in cardiac structures by in situ hybridization was also previously shown to occur in fish by our group (Gavaia et al., 2006; Ortiz-Delgado et al., 2006; Pinto et al., 2003). The presence of high levels of $m g p$ in heart tissue is indicative of its function as a calcification inhibitor since this tissue has been shown to be a target of ectopic calcifications during pathological conditions, where expression and/or function of mgp is altered (Jono et al., 2006; Luo et al., 1997; Proudfoot and Shanahan, 2006; Schurgers et al., 2005). Mgp is reported to act in the cardiovascular system as a regulator of calcium deposition by binding calcium ions and crystals, by modulating bone morphogenetic protein-2, by binding to extracellular matrix (ECM) and as a regulator of apoptosis (Braam et al., 2000; Hruska et al., 2005; Proudfoot and Shanahan, 2006).
Vertebrae and kidney, in contrast with heart and branchial arches, showed very low levels of mgp mRNA by qPCR although expression in these tissues was confirmed by in situ hybridization. In vertebrae, mgp expression was associated mainly to the proliferating and differentiated chondrocytes from the intervertebral cartilage, in agreement with previous reports (Gavaia et al., 2006; Pinto et al., 2003), and to the notochord, in particular the chordoblasts.

In the kidney, mgp expression was detected in some renal tubules and glumeruli which can be related to a need for inhibition of mineralization in this organ, a process which could be mediated by Mgp. It is known that nephrocalcinosis is a common disease affecting aquaculture produced fish (Gillespie and Evans, 1979; Golomazou et al., 2006; Srinivasa and Lakshmi, 1986), and Mgp presence in this organ can be explained by the need of preventing passive accumulation of calcium Expression of $m g p$ in kidney assessed by Northern blotting or qPCR was reported in various studies in fish and mammals (Fraser and Price, 1998; Pinto et al., 2003; Simes et al., 2003; Zhao and Nishimoto, 1996), although only few studies referred to in situ localization of mgp expression on this organ, namely in rat (Mus musculus) (Zhao and Nishimoto, 1996) and in blue shark (Ortiz-Delgado et al., 2006). 

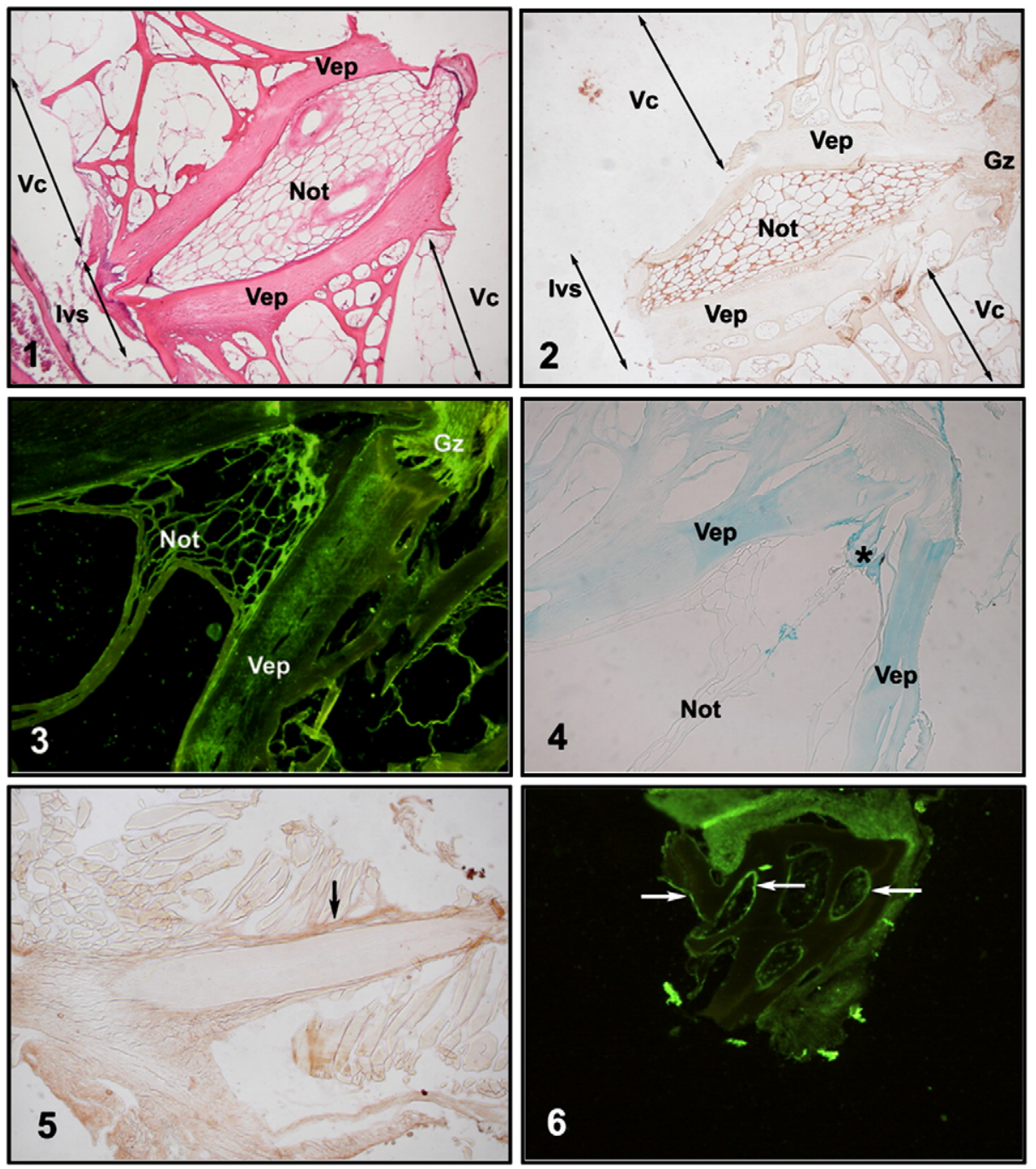

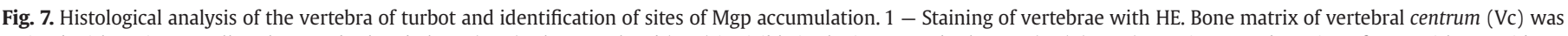

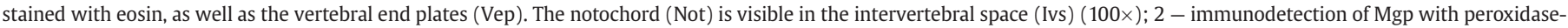

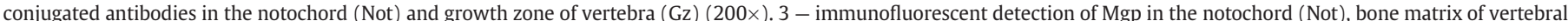

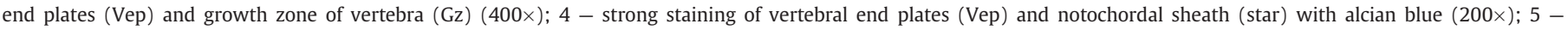

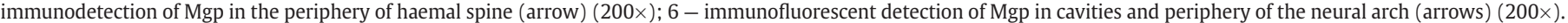

4.3. Mgp accumulates in proliferating chondrocytes, in growth fronts during bone mineralization and in notochord cells

Immunostaining showed Mgp accumulation in the gills only at sites of proliferating chondrocytes from Zellknorpel cartilage of branchial filaments (Fig. 6). A similar pattern of Mgp accumulation was previously observed in branchial filaments of meagre (Simes et al., 2003).

In turbot vertebrae, Mgp accumulation was observed at four different sites (Fig. 7). The immunodetection of Mgp in the mineralizing fronts of vertebral arches and spines, and in vertebral
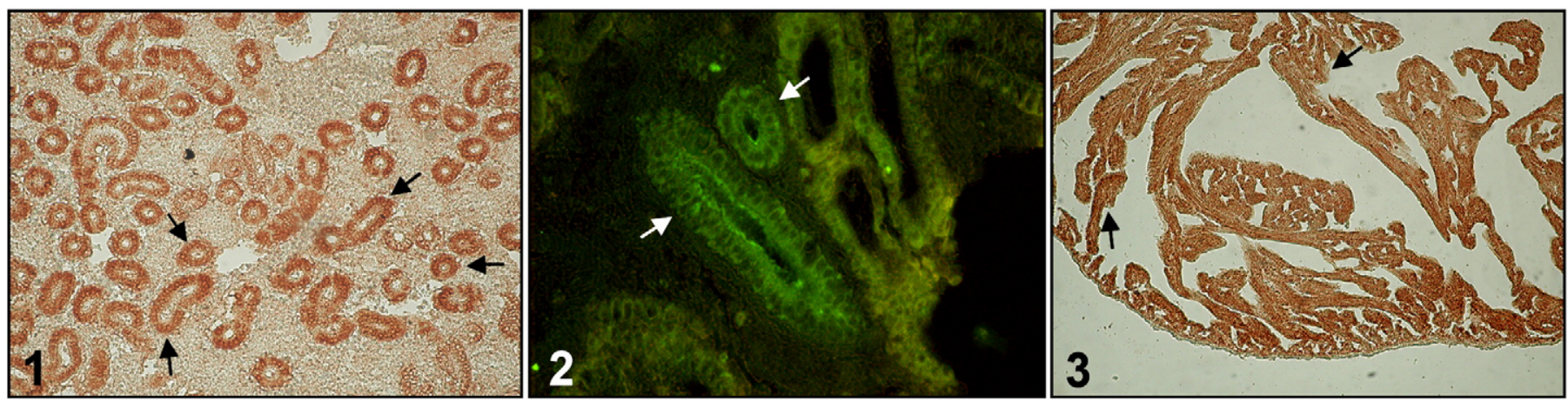

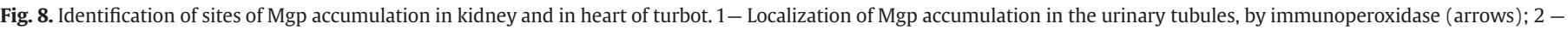

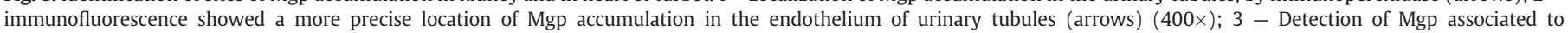
cardiomyocytes in a transverse section of a juvenile specimen heart $(400 \times)$. 
growth zones, corroborates previous findings in vertebrates which indicated that Mgp appears first in sites that will be later calcified, functioning early in the bone formation process (Otawara and Price, 1986). The presence of Mgp in these sites may result from the fact that in fish, bone growth occurs (i) in the contact area of opposing vertebral body end plates (Witten et al., 2005), and (ii) at the periphery of arches and spines. Our work is in agreement with other studies which have also reported the presence of Mgp in the mineralization front in fish (Pinto et al. 2003 for gilthead seabream; Simes et al. 2003 for meagre; among other authors).

Furthermore, Mgp accumulation was evident in the matrix of vertebral end plates from turbot, a site near vertebrae growth zone. The positive staining with alcian blue in a contiguous slide seems to indicate that this matrix is still undergoing calcification. This result is in contrast with that found in meagre (Simes et al., 2003) where Mgp was restricted to cartilage but is in agreement with the results of Gavaia et al. (2006) for zebrafish and Senegalese sole.

Immunofluorescence and immunohistochemistry revealed accumulation of Mgp in the notochord cells, both chordoblasts and chordocytes. Since no reports of Mgp accumulation and/or expression in the notochord structures were found in the literature, this is the first report of Mgp accumulation in this structure. The presence of Mgp in this site could be related to a possible role of Mgp in teleost osteogenesis while also preventing local calcification, in agreement with its proposed function in fish and mammals.

\subsection{In soft tissues, Mgp accumulates essentially in heart and kidney}

Immunodetection of Mgp in soft tissues was positive in heart and kidney (Fig. 8), a finding that could be related to its alleged protection role against ectopic calcification of soft tissues. Alternatively, and since Mgp is present in the vascular system, it could be argued that the levels observed were due to the high degree of vascularization of these two organs. However, this explanation is unlikely since liver is also highly vascularized but no accumulation of Mgp was detected in this organ.

In kidney, accumulation of Mgp was immunodetected in the renal tubules corroborating the results obtained for the expression of this protein. Our results confirm previous reports of Mgp accumulation in kidney by Ortiz-Delgado et al. (2006) for blue shark and Zhao and Nishimoto (1996) for rat. The fact that only few articles report this accumulation might be the time scale of Mgp expression/accumulation in kidney, as demonstrated by Zhao and Nishimoto, 1996, and/or the possibility that the need for this protein in kidney may vary among species.

In this report, in addition to the presence of $m g p$ mRNA detected in heart tissue, we were also able to detect Mgp accumulation in heart cells and ECM by immunostaining, suggesting that this accumulation could be related to its role as a calcification inhibitor. The only reference reporting a similar accumulation for Mgp in mammalian was in the work from Fraser and Price (1988), who were able to quantify Mgp in rat heart by RIA, detecting minute amounts compared to calcified tissues. These authors attributed its location to cardiomyocytes by immunofluorescence. The presence of Mgp in arterial walls, expressed by vascular smooth muscle cells, is also well documented, suggesting its involvement in the prevention of vascular calcification and atherosclerotic plate formation (Dhore et al., 2001; Engelese et al., 2001; Proudfoot and Shanahan, 2006). Thus, a similar effect in heart tissue is a likely possibility, since heart valves are also a site of calcification in pathological conditions (Price et al., 1998; Proudfoot and Shanahan, 2006). Mgp accumulation in heart structures of other fish (aorta and cardiac arterial bulbus) was previously described in Senegalese sole (Gavaia et al., 2006) and in blue shark (Ortiz-Delgado et al., 2006), confirming that a conservation of specific cardiac accumulation of Mgp is widespread among very different taxa which reinforces the hypothesis of a conserved function crucial for all studied vertebrates.
In conclusion, the results presented in this report strongly suggest that in turbot, Mgp expression and function is associated with regulation of mineralization, and provides further evidence confirming that bony fish are indeed useful models to study function, regulation and expression of Mgp. The identification of Mgp in the notochord cells is a novel finding and opens new perspectives for Mgp function in this tissue. In addition we report the intracellular localization of $m g p$ in fish heart, in agreement with an older report for rat (Fraser and Price, 1988) which provides additional evidence for a conserved role for Mgp in heart tissue.

\section{Acknowledgements}

This work was partially funded by FCT (Portuguese Science and Technology Foundation), grant FISHDEV POCTI/CVT/42098/2001, including funding from POCI 2010 and UE funds from FEDER and by MCYT (Spanish Ministerio de Ciencia y Tecnología), grant SPARUGENES MCYT/AGL2003-03558. Vânia Roberto was a recipient of PhD fellowships (SFRH/BD/38607/2007).

\section{References}

Benjamin, M., Ralphs, J.R., Eberewariye, O.S., 1992. Cartilage and related tissues in the trunk and fins of teleosts. J. Anat. 181, 113-118.

Braam, L.A.J.L.M., Dissel, P., Gijsbers, B.L.M.G., Spronk, H.M.H., Hamulyak, K., Soute, B.A M., Debie, W., Vermeer, C., 2000. Assay for human matrix Gla protein in serum. Potential applications in the cardiovascular field. Arterioscler. Thromb. Vasc. Biol. 20, 1257-1261.

Cancela, M.L., Ohresser, M.C.P., Reia, J.P., Viegas, C.S.B., Williamson, M.K., Price, P.A., 2001 Matrix Gla protein in Xenopus laevis: molecular cloning, tissue distribution and evolutionary considerations. J. Bone Min. Res. 16, 1611-1622.

Conceição, N., Henriques, N.M., Ohresser, M.C.P., Hublitz, P., Schule, R., Cancela, M.L., 2002. Molecular cloning of the matrix Gla protein gene from Xenopus laevis: functional analysis of the promoter identifies a calcium sensitive region required for basal activity. Eur. J. Biochem. 269, 1947-1956.

Dhore, C.R., Cleutjens, J.P.M., Lutgens, E., Cleutjens, K.B.J.M., Geusens, P.P.M., Kitslaar, P.J E.H.M., Tordoir, J.H.M., Spronk, H.M.H., Vermeer, C., Daemen, M.J.A.P., 2001 Differential expression of bone matrix regulatory proteins in human atherosclerotic plaques. Arterioscler. Thromb. Vasc. Biol. 21, 1998-2003.

Du, S.J., Frenkel, V., Kindschi, G., Zohar, Y., 2001. Visualizing normal and defective bone development in zebrafish embryos using the fluorescent chromophore calcein. Dev. Biol. 238, 239-246.

Engelese, M.A., Neele, J.M., Bronckers, A.L.J.J., Pannekoek, H., deVries, C.J.M., 2001 Vascular calcification: expression patterns of the osteoblast-specific gene core binding factor alpha-1 and the protective factor matrix gla protein in human atherogenesis. Cardiovasc. Res. 52, 281-289.

Fraser, J.D., Price, P.A., 1988. Lung, heart, and kidney express high levels of mRNA for the vitamin K-dependent matrix Gla protein. J. Biol. Chem. 23, 11033-11036.

Gavaia, P.J., Simes, D.C., Ortiz Delgado, J.B., Viegas, C.S.B., Pinto, J.P., Kelsh, R.N., Sarasquete, C., Cancela, M.L., 2006. Osteocalcin and matrix Gla protein in zebrafish (Danio rerio) and Senegal sole (Solea senegalensis): comparative gene and protein expression during larval development through adulthood. Gene Expr. Patterns 6 (6), 637-652.

Gillespie, D.C., Evans, R.V., 1979. Composition of granules from kidneys of rainbow trout (Salmo gairdneri) with nephrocalcinosis. J. Fish. Res. Bd Can. 36, 683-685.

Golomazou, E., Athanassopoulou, F., Vagianou, S., Sabatakou, O., Tsantilas, H., Rigos, G., Kokkokiris, L., 2006. Diseases of white sea bream (Diplodus sargus L.) reared in experimental and commercial conditions in Greece. Turk. J. Vet. Anim. Sci. 30, 389-396.

Grotmol, S., Nordvik, K., Kryvi, H., Totland, G.K., 2005. A segmental pattern of alkaline phosphatase activity within the notochord coincides with the initial formation of the vertebral bodies. J. Anat. 206, 427-436.

Hale, J.E., Fraser, J.D., Price, P.A., 1988. The identification of matrix Gla protein in cartilage. J. Biol. Chem. 263, 5820-5824.

Hao, H., Hirota, S., Tsukamoto, Y., Imakita, M., Ishibashi-Ueda, H., Yutani, C., 1995. Alterations of bone matrix protein mRNA expression in rat aorta in vitro. Arterioscler. Thromb. Vasc. Biol. 15, 1474-1480.

Hashimoto, F., Kobayashi, E.T., Sakai, E., Kobayashi, K., Shibata, M., Kato, Y., Sakai, H. 2001. Expression and localization of MGP in rat tooth cementum. Arch. Oral Biol. 46 585-592.

Hruska, K.A., Mathew, S., Saab, G., 2005. Bone morphogenetic proteins in vascular calcification. Circ. Res. 97, 105-114.

Jono, S., Shioi, A., Ikari, Y., Nishizawa, Y., 2006. Vascular calcification in chronic kidney disease. J. Bone Miner. Metab. 24, 176-181.

Lagler, K., Bardach, J., Miller, R., Passino, D.M., 1987. Ichthyology, 2nd edition. John Wiley \& Sons, Inc, USA. 506 pp.

Laizé, V., Martel, P., Viegas, C.S.B., Price, P.A., Cancela, M.L., 2005. Evolution of matrix and bone $\gamma$-carboxyglutamic acid proteins in vertebrates. J. Biol. Chem. 280 (29), 26659-26668. 
Luo, G., Ducy, P., McKee, M.D., Pinero, G.J., Loyer, E., Behringer, R.R., Karsenty, G., 1997. Spontaneous calcification of arteries and cartilage in mice lacking matrix GLA protein. Nature 358, 78-81.

Marshal, P.T., Hughes, G.M., 1985. The skeleton and muscles. Physiology of Mammals and Other Vertebrates. InCambridge University Press, pp. 186-199.

Meier, M., Weng, L.P., Alexandrakis, E., Ruschoff, J., Goeckenjan, G., 2001. Tracheobronchial stenosis in Keutel syndrome. Eur. Respir. J. 17, 566-569.

Newman, B., Gigout, L.I., Sudre, L., Grant, M.E., Wallis, G.A., 2001. Coordinated expression of matrix Gla protein is required during endochondral ossification for chondrocyte survival. J. Cell Biol. 154, 659-666.

Ortiz-Delgado, J.B., Simes, D.C., Gavaia, P., Sarasquete, C., Cancela, M.L., 2005. Osteocalcin and matrix GLA protein in developing teleost teeth: identification of sites of mRNA and protein accumulation at single cell resolution. Histochem. Cell Biol. 124 (2), $123-130$.

Ortiz-Delgado, J.B., Simes, D.C., Viegas, C.S.B., Schaff, B.J., Sarasquete, C., Cancela, M.L. 2006. Cloning of matrix Gla protein in a marine cartilaginous fish, Prionace glauca: preferential protein accumulation in skeletal and vascular systems. Histochem Cell Biol. 126, 89-101.

Otawara, Y., Price, P.A., 1986. Developmental appearance of matrix Gla protein during calcification in the rat. J. Biol. Chem. 261, 10828-10832.

Pinto, J.P., Conceição, N., Gavaia, P.J., Cancela, M.L., 2003. Matrix Gla protein gene expression and protein accumulation co-localize with cartilage distribution during development of the teleost fish Sparus aurata. Bone 32, 201-210.

Price, P.A., Fraser, J.D., Metz-Virca, G., 1987. Molecular cloning of matrix Gla protein: implications for substrate recognition by the vitamin K-dependent $\gamma$-carboxylase. Proc. Natl. Acad. Sci. U. S. A. 84, 8335-8339.

Price, P.A., Rice, J.S., Williamson, M.K., 1994. Conserved phosphorylation of serine in the Ser-X-glu/Ser (P) sequences of the vitamin K-dependent matrix Gla protein from shark, lamb, rat, cow and human. Protein Sci. 3, 822-830.

Price, P.A., Faus, S.A., Williamson, M.K., 1998. Warfarin causes rapid calcification of the elastic lamellae in rat arteries and heart valves. Arterioscler. Thromb. Vasc. Biol. 18, 1400-1407.

Proudfoot, D., Skepper, J.N., Shanahan, C.M., Weissberg, P.L., 1998. Calcification of human vascular cells in vitro is correlated with high levels of matrix Gla protein and low levels of osteopontin expression. Arterioscler. Thromb. Vasc. Biol. 18, 379-388.

Proudfoot, D., Shanahan, C.M., 2006. Molecular mechanisms mediating vascular calcification: role of matrix Gla protein. Nephrology 11, 455-461.

Sanatamaría, J.A., Andrades, J.A., Herráez, P., Fernández-Llebrez, P., Becerra, J., 2005 Perinotochordal connective sheet of gilthead sea bream larvae (Sparus aurata, L.) affected by axial malformations: a histochemical and immunocytochemical study. The Ana. Record 240 (2), 248-254

Schurgers, L.J., Teunissen, K.J.F., Knapen, M.H.J., Kwaijtaal, M., Diest, R., 2005. Novel conformation-specific antibodies against matrix -carboxyglutamic acid (Gla) protein undercarboxylated matrix Gla protein as marker for vascular calcification. Arterioscler. Thromb. Vasc. Biol. 25, 1629-1633.

Simes, D.C., Williamson, M.K., Ortiz-Delgado, J.B., Viegas, C.S.B., Price, P.A., Cancela, M.L., 2003. Purification of matrix Gla protein from a marine teleost fish, Argyrosomus regius: calcified cartilage and not bone as the primary site of MGP accumulation in fish. J. Bone Min. Res. 18, 244-259.

Simes, D.C., Williamson, M.K., Schaff, B.J., Gavaia, P.J., Ingleton, P.M., Price, P.A., Cancela, M.L., 2004. Characterization of osteocalcin (BGP) and matrix Gla protein (MGP) fish specific antibodies: validation for immunodetection studies in lower vertebrates. Calcif. Tissue Int. 74, 170-180.

Speer, M.Y, McKee, M.D., Guldberg, R.E, Liaw, L, Yang H.Y, Tung E, Karsenty, G. Giachelli, C.M., 2002. Inactivation of the osteopontin gene enhances vascular calcification of matrix Gla protein-deficient mice: evidence for osteopontin as an inducible inhibitor of vascular calcification in vivo. J. Exp. Med. 196, 1047-1055.

Srinivasa, K., Lakshmi, K., 1986. Case study of nodular excrescences in Arius tenuispinis, hitherto considered as osteoma. Dis. Aquat. Org. 1, 123-130.

Viegas, C.S.B., Simes, D.C., Laizé, V., Williamson, M.K., Price, P.A., Cancela, M.L., 2008. Glarich protein (GRP): a new vitamin K-dependent protein identified from sturgeon cartilage and highly conserved in vertebrates. J. Biol. Chem. 283 (52), 36655-36664.

Walker Jr., W.F., Liem, K.F., 1994. Functional anatomy of the vertebrates, An Evolutionary Perspective, 2nd ed. Saunders College Publications, Philadelphia, USA. 788pp.

Wallin, R., Wajih, N., Greenwood, G.T., Sane, D.C., 2001. Arterial calcification: a review of mechanisms, animal models, and the prospects for therapy. Med. Res. Rev. 21 (4), 274-301.

Witten, P.E. Gil-Martens, L, Hall, B.K. Huysseune, A, Obach, A., 2005. Compressed vertebrae in Atlantic salmon Salmo salar: evidence for metaplastic chondrogenesis as a skeletogenic response late in ontogeny. Dis. Aquat. Org. 64, 237-246.

Yagami, K., Suh, J.Y., Enomoto-Iwamoto, M., Koyama, E., Abrams, W.R., Shapiro, I.M., Pacifici, M., Iwamoto, M., 1999. Matrix GLA protein is a developmental regulator of chondrocyte mineralization and, when constitutively expressed, blocks endochondral and intramembranous ossification in the limb. J. Cell Biol. 147, 1097-1108.

Zhao, J., Nishimoto, S.K., 1996. Matrix Gla protein gene expression is elevated during postnatal development. Matrix Biol 15 (2), 131-140. 